\title{
Avaliação das modificações hidrológicas ocorridas na Estação de Porto São José, situada em um trecho do rio Paraná regulado por Usinas Hidrelétricas
}

\section{Evaluation of hydrological modifications that occurred at Porto São José Station in a reach of the Paraná river regulated by hydroelectric power plants}

Luiz Henrique Maldonado; Paulo Everardo Muniz Gamaro² e Jessica Martins dos Santos ${ }^{3}$

${ }^{1,2,3}$ Itaipu Binacional, Foz do Iguaçu, PR

lhmaldo@itaipu.gov.br; pemg@itaipu.gov.br; martinsj@itaipu.gov.br

Recebido: 10/12/14 - Revisado: 28/01/15 - Aceito: 28/05/15

\section{RESUMO}

As Usinas Hidrelétricas (UHE) possuem importante representação no cenário energético brasileiro, sendo a base para o Sistema Interligado Nacional (SIN). Entretanto, uma das consequências das operações das UHEs são as alterações dos regimes hidrológicos naturais dos sistemas fluviais, tanto à montante quanto à jusante da barragem. Em vista disso, o presente trabalho faz uma análise das possiveis alterações hidrológicas em uma estação fluviométrica situada à jusante de UHE, baseando-se em campanhas de campo, como medições de vazão realizadas no periodo de 1965 a 2014, levantamentos batimétricos e serie histórica de nivel d'água. Os resultados obtidos para a Estação de Porto São José (PSJ), no rio Paraná, situada 30 km à jusante das UHE Porto Primavera e UHE Rosana, indicam a ocorrência de um processo de erosão na seção de PSJ, com um aumento da área molhada de $28 \%$ e redução da velocidade média de 20\%. Em vista destas alterações, foi determinada uma nova curva-chave para condição de escoamento permanente e foi identificada e corrigida a condição de escoamentos não permanentes (bistereses) em PSJ. Assim, considerando o somatório das defluências das UHEs como referência, a tabela de calibragem indica desvios mensais de $-500 \mathrm{~m}^{3} \cdot \mathrm{s}^{-1}$, a curva-chave para escoamento permanente desvios de -90 $\mathrm{m}^{3} . \mathrm{s}^{-1}$ e a curva-chave para escoamentos não permanentes desvios de-75 $\mathrm{m}^{3} . \mathrm{s}^{-1}$. Apesar da curva-chave para escoamento permanente apresentar pequenos desvios mensais (-90 $\left.\mathrm{m}^{3} . \mathrm{s}^{-1}\right)$, em função da demanda energética diária as defluências das UHEs ocasionam desvios horários em PSJ de +640 a-610 $\mathrm{m}^{3} \cdot \mathrm{s}^{-1}$ (média de $17 \mathrm{~m}^{3} \cdot \mathrm{s}^{-1}$ ). Assim, a regularização das vazões no trecho do rio Paraná ocasionou alterações de variáveis hidrológicas e hidráulicas em PSJ (e.g., área, velocidade, escoamento para condição não permanente) e que puderam ser corretamente representadas pelas curvas-chave definidas por contínuas campanhas de campo.

Palavras Chave: Usinas hidrelétricas. Curva -chave. Histerese

\begin{abstract}
Hydroelectric Plants (UHE- Usinas Hidroeletricas) are importantly represented on the Brazilian energy scene, and provide the base for the National Interconnected System (SIN Sistema Interligado Nacional). However, one of the consequences of UHE operation is changes in the natural hydrological regimes of the river system both upstream and downstream from the dam. For this reason this paper analyzes the possible bydrological changes at a riverganging station downstream from a bydropower plant, based on field campaigns with flow measurements carried out during the period from 1965 to 2014, bathymetric surveys and historical series of water levels The results obtained for Porto São José Station (PSJ) in Paraná river, 30 km downstream from UJE Porto Primavera and UHE Rosana, indicate the occurrence of erosion in the PSJ section with a $28 \%$ increase in the wetted area and $20 \%$ reduction of mean velocity. Because of these changes a new rating curve was determined for the permanent flow condition, and the non-permanent flow condition (bysteresis) was identified and corrected for PSJ. Thus, taking the sum total of outflows from the UHEs as reference, the calibration table indicates monthly deviations of $-500 \mathrm{~m}^{3} \mathrm{~s}^{-1}$, the rating curve for permanent flow deviations of $-90 \mathrm{~m}^{3} \mathrm{~s}^{-1}$, and the rating curve for non permanent flows deviations of -75 $\mathrm{m}^{3}$ s-1. Although the rating curve for permanent flows presents small monthly deviations $\left(-90 \mathrm{~m}^{3} \mathrm{~s}^{-1}\right)$, because of the daily energy demands, the outflows from the UHE cause hourly deviations at PSJ of +640 to $-610 \mathrm{~m}^{3} \mathrm{~s}^{-1}$ (mean of $17 \mathrm{~m}^{3} \mathrm{~s}^{-1}$ ). Thus flow regulation in this reach of Paraná River caused alterations of bydrological and bydraulic variables at PSJ (e.g. area, velocity, runoff for non-permanent condition) which could be correctly represented by rating curves defined by continuous field campaigns.
\end{abstract}

Keywords: Hydroelectric Plants. Rating curves. bysteresis 


\section{INTRODUÇÃO}

A geração de energia elétrica no Brasil baseia-se na hidroeletricidade, com 584 reservatórios em operação, dos quais 147 são usinas hidrelétricas de geração (UHE, potência superior a 30MW) e 256 pequenas centrais hidrelétricas (PCHs, potência entre 1 a 30 MW) (CAMPAGNOLI; DINIZ, 2012). A hidroeletricidade assume, assim, especial importância e é a base do suprimento energético brasileiro (MÜLLER, 1995).

Segundo Campagnoli e Diniz (2012), em função do programa de monitoramento proposto para cada obra hidráulica, nos períodos anteriores ao enchimento dos reservatórios são necessárias intensivas investigações hidrometeorológica da bacia de interesse (e.g., levantamento topobatimétrico, condições meteorológicas da bacia, curva de permanência para vazão e nível d'água).Em função dos dados coletados em campo, para cada estação fluviométrica são determinadas as séries de vazão (hidrogramas), tanto para realizar o dimensionamento da obra, quanto para ser um dado de suporte a operação do empreendimento.

Entretanto, de acordo com Sousa (2000) esses empreendimentos, de uma forma geral, produzem impactos sobre o meio ambiente, que são verificados ao longo do tempo de vida da usina, bem como ao longo do espaço físico envolvido.

A partir da construção da barragem de uma hidrelétrica, o rio em que o empreendimento foi inserido passa a ser gerido não mais por seus pulsos naturais, mas pela dinâmica produtiva da usina, ocasionando profundas modificações hidrológicas nos sistemas fluviais como um todo, tanto a sua jusante como a sua montante (SIQUEIRA et al., 2013).

Tais regiões, em especial à montante das barragens, deveriam ser amplamente monitoradas e estudadas em função da sua importância para a operação da usina e controle da vida útil do reservatório. Porém, não menos modificada, muito embora menos investigada, é a região à jusante das barragens (MANYARI, 2007). As operações das barragens promovem modificações no regime de fluxo e de transporte de sedimentos e introduzem um novo processo no canal, podendo causar efeitos substanciais na estabilidade do rio à jusante.

As alterações mais evidentes são as variações nas vazões e velocidades de fluxo, as alterações na quantidade, tipo e granulometria dos sedimentos transportados e alterações morfológicas dos canais, dentre outras (SIQUEIRA et al., 2013).

Para avaliar os efeitos transformadores provocados pelas barragens ao longo do tempo é necessário acompanhar as mudanças morfológicas, através de batimetrias periódicas e monitorar a validade da relação entre nível d'água e vazão (curva-chave).

No entanto, mesmo supondo-se que os dados oriundos da curva-chave forneçam resultados satisfatórios, julga-se necessário fazer aferições com dados medidos, pois a relação existente entre vazão e cota de um rio é uma função complexa que envolve características hidráulicas e geométricas da seção (JACCON; CUDO, 1989). Em certas situações, algumas técnicas podem auxiliar na obtenção das curvas-chave, como a teoria do caos, redes neurais e lógica de fuzzy (KHATIBI et al., 2012). Além disso, algumas curvas-chave são consideradas temporárias e variam constantemente, em função da alteração da área, aumentando as incertezas (JALBERT; MATHEVET; FAVRE, 2011).

Considerando trechos de rios regularizados por UHEs, a produção energética ao longo do dia das barragens ocasionam oscilações do nível d'água, que podem modificar o escoamento para condição não permanente, tornando a relação "cota $x$ vazão" como não unívoca.

Além disso, a metodologia para a obtenção da vazão deve ser modificada, pois uma medição convencional (e.g., molinete) apresentaria imprecisões para a determinação da vazão, em função das oscilações do nível d'água, principalmente pelo tempo demandado durante o processo. Uma das alternativas é a aplicação dos métodos acústicos para medição de vazão.

Segundo Mueller et al. (2013), as medições acústicas são realizadas com o equipamento "Acoustic Doppler Current Profiler" (ADCP) e, em geral, com o barco em movimento. Os ADCPs são utilizados há mais de 25 anos e são capazes de medir velocidades d'água e vazão em rios e canais com grandes profundidades (maior que 5 metros), assim como em pequenas profundidades $(30 \mathrm{~cm})$. Além disso, o ADCP permite aos hidrólogos redução de tempo para a realização das atividades e permite uma medição da velocidade da água em escalas temporais e espaciais diferenciadas.

A determinação das reais vazões é fundamental para que as operações de Usinas Hidrelétricas sejam confiáveis. A Estação de Porto São José (PSJ), rio Paraná, pode ser utilizada como condição de contorno para modelos hidrodinâmicos de jusante para as Usinas de Porto Primavera e Rosana (situadas à montante de PSJ). Além disso, as vazões de PSJ são utilizadas como uma das variáveis importantes na previsão de afluência para a Usina de Itaipu Binacional (situada à jusante de PSJ), sendo fundamental o seu conhecimento da precisão desta informação.

Assim, objetivou-se avaliar, sob o aspecto quantitativo, as mudanças das variáveis hidrológicas, geométricas e morfológicas da estação fluviométrica Porto São José, que está situada no rio Paraná, em um trecho regulado por Usinas Hidrelétricas.

\section{MATERIAL E MÉTODOS}

\section{Localização}

\section{A. Estação Fluviométrica Porto São José}

A Estação de Porto São José, código ANA 64.575.000, está localizada no rio Paraná, latitude $22^{\circ} 71^{\prime} 78,16$ 'S, longitude $53^{\circ} 17^{\prime}$ 67,63’W (WGS84), 35km à jusante das UHEs Porto Primavera e Rosana, Município de São Pedro do Paraná, Estado do Paraná.

A seção de réguas está localizada na margem esquerda do rio Paraná, à montante da balsa que faz a travessia entre Porto São José e Baitaporã, dentro do terreno do governo do estado do Paraná (Figura 1).

O monitoramento fluviométrico iniciou-se no dia 4 de novembro de 1963, pela CESP, e a partir de março de 1989 a Itaipu Binacional vem monitorando a Estação.

A partir de 1977, o nível d'água (N.A.) mínimo iden- 
tificado na série histórica foi de 1,12m no dia 09 de julho de 2001 e o valor máximo de N.A. medido foi de $8,74 \mathrm{~m}$ no dia 18 de fevereiro de 1983. A seção de medição (PRSJA) encontra-se 50 metros à jusante da seção de réguas.

Os perfis batimétricos são realizados a cada 2 ou 3 anos, sendo o último realizado no dia 04 de junho de 2008. Além das batimetrias convencionais, são realizadas batimetrias em conjunto com as medições de vazão com uma maior frequência. Considerando o perfil batimétrico, as cotas de extravasamento são 7,12m (margem direita) e 15,3m (margem esquerda).
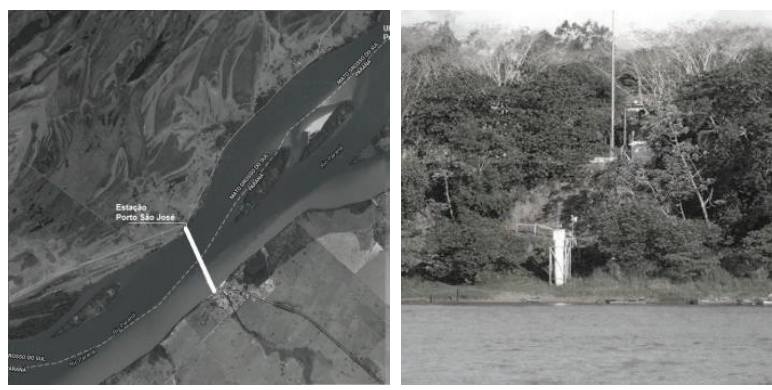

Figura 1- Localização da Estação Porto São José Fonte: Google Earth 2014

A curva-chave vigente da estação foi elaborada em março de 1989, por intermédio do Consórcio Themag/GCAP, intitulada como Tabela de Calibragem, uma modificação da Tabela de Calibragem emitida pela CESP em 1983.

A partir de 1980, à montante da estação, grandes obras foram iniciadas para a construção de duas Usinas Hidrelétricas: UHE Porto Primavera, localizada no rio Paraná, e a UHE Rosana, no rio Paranapanema.

\section{B. Usina Hidrelétrica Porto Primavera}

A Usina Hidrelétrica Engenheiro Sérgio Motta, também chamada de Usina Hidrelétrica Porto Primavera, está localizada no rio Paraná na divisa dos municípios de Rosana (SP) e Baitaporã (MS), a aproximadamente $28 \mathrm{~km}$ à montante da confluência com o Rio Paranapanema (Figura 2).

Administrada pela CESP, a usina possui a barragem mais extensa do Brasil, com 10.186m de comprimento, possuindo um reservatório de $2.250 \mathrm{~km}^{2}$. O projeto foi iniciado no ano de 1980 e começou a operar comercialmente 18 anos depois, em 1998. A UHE possui 14 unidades geradoras, totalizando 1.540MW de potência instalada.

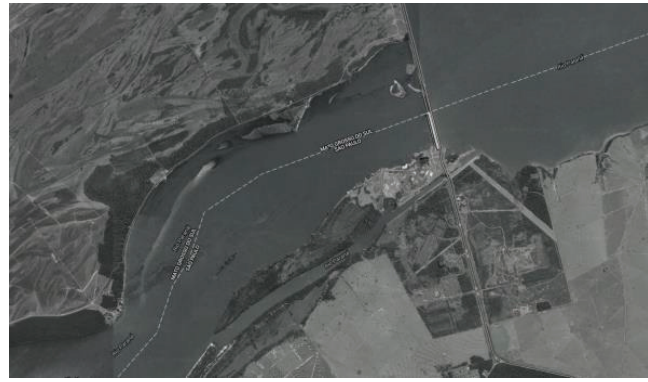

Figura 2 - Localização da UHE Porto Primavera Fonte: Google Earth 2014

\section{Usina Hidrelétrica Rosana}

A UHE Rosana é a última usina do rio Paranapanema. Localiza-se entre os municípios paulistas de Rosana e Teodoro Sampaio, e Diamante do Norte no estado do Paraná, a 15 km da confluência com o rio Paraná, na região conhecida como Pontal do Paranapanema (Figura 3).

As obras da usina foram iniciadas em 1980 e os primeiros geradores entraram em operação em março de 1987. Os demais grupos geradores foram instalados em 1994 e 1996, totalizando uma potência de $372 \mathrm{MW}$.

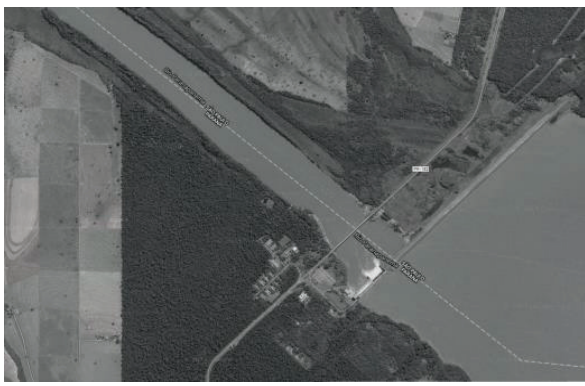

Figura 3 - Localização da UHE Rosana Fonte: Google Earth 2014

\section{Medições de vazão}

Na Estação de Porto São José, no período de 1965 a 1988 foram realizadas 359 medições de vazão com o método tradicional (e.g., molinete ancorado), disponibilizadas pelo DNAEE e obtidas no arquivo técnico da Itaipu Binacional (Figura 4a). Para o período de 1989 a 2004, a Itaipu Binacional realizou 60
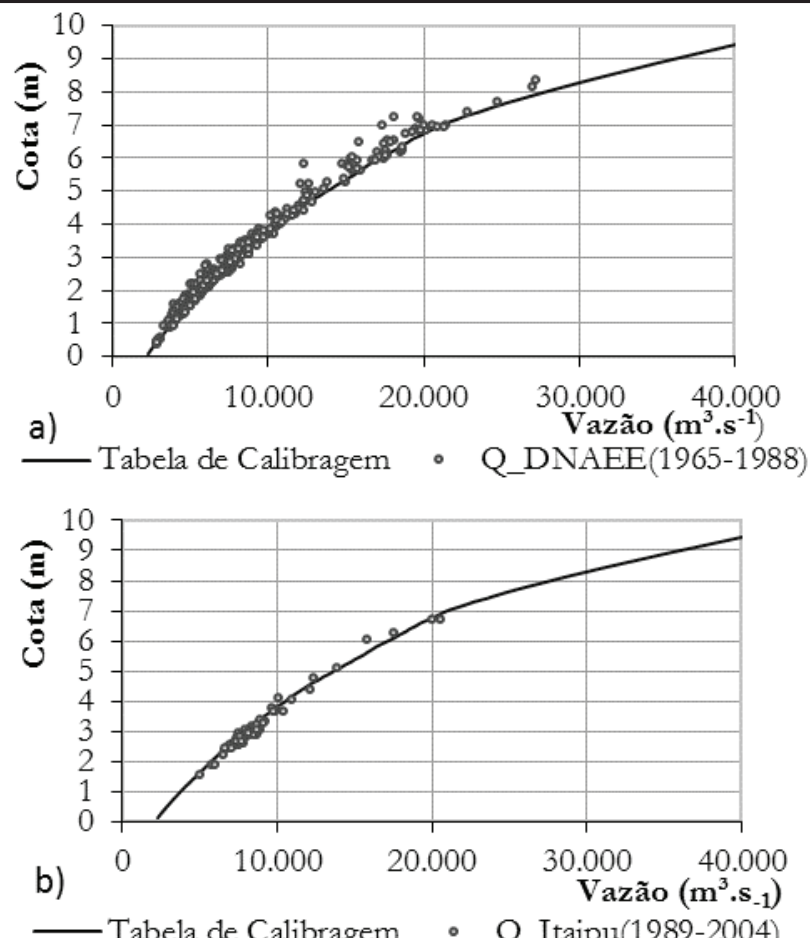

Figura 4 - Tabela de Calibragem (1983) e medições de vazão: (a) de 1965 a 1988 (DNAEE); (b) 1989 a 2004 (Itaipu Binacional) 


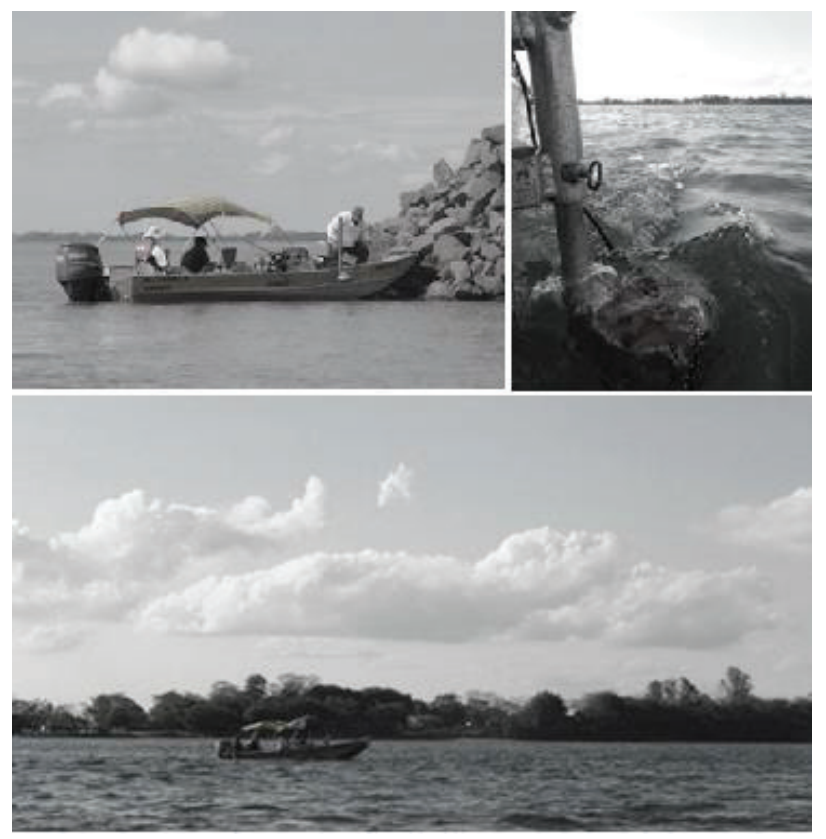

Figura 5 - Equipe de Hidrometria da Itaipu Binacional realizando medições de vazão em Porto São José
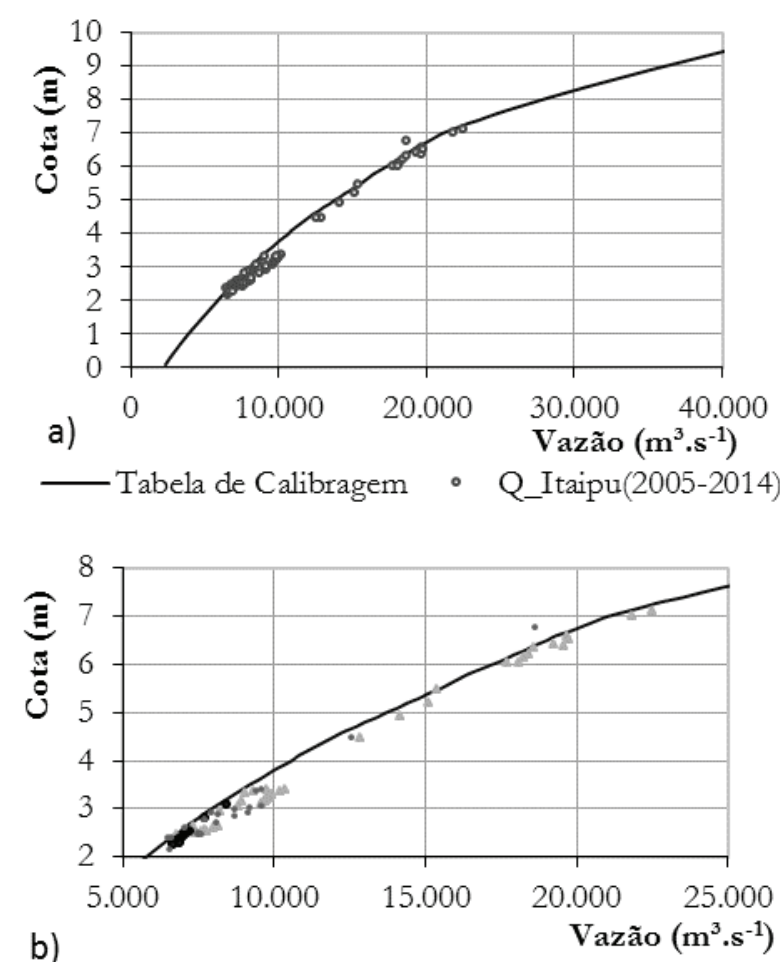

b)
- Q_1200

Figura 6 - (a) Tabela de Calibragem e medições de vazão de 2005 a 2014; (b) medições separadas pelo tipo de equipamento, como: $600 \mathrm{kHz}, 1200 \mathrm{kHz}$ e modelo ADP-M9 medições de vazão na Estação, sendo 44 delas obtidas com o método convencional e 16 medições com o método acústico (modelos de $600 \mathrm{kHz}$ e $300 \mathrm{kHz}$ ) (Figura 4b).

Para o período de 2005 até 2014 foram realizadas 87 medições de vazão com o método acústico, com diferentes modelos de equipamentos, fabricantes, frequências e processamentos acústicos (e.g., RioGrande $600 \mathrm{kHz}, 1200 \mathrm{kHz}$ e ADP-M9, processamento BroadBand e Narrowband) (Figuras 5 e 6). Em 2013, foi realizada uma campanha intensiva de medição de vazão, ao longo de três dias, em função das variações das defluências das UHEs (ITAIPU, 2013).

Para realizar as medições acústicas de vazão, normas e procedimentos foram aplicados durante as campanhas, como os apresentados por: ISO (2005), WMO (2010) e Gamaro (2012).

A partir das vazões apresentadas (Figuras 4 e 6 ), foram analisados os desvios de vazão obtidos entre a tabela de calibragem e as vazões medidas, considerando-os em ordem cronológica e ordem crescente de nível d'água.As vazões obtidas pela tabela de calibragem também foram comparadas com o somatório de defluência entre as UHEs, considerando médias diárias.

Além disso, foram plotadas as velocidades médias medidas em cada campanha, em função do nível d'água, e determinadas equações de correlação, por intermédio do método dos mínimos quadrados.

\section{Série de nível d'água}

Considerando as leituras manuais nas réguas às 7, $12 \mathrm{e}$ 17h, de 1977 até 2013, foi construída a série histórica de nível d'água (N.A.) (Figura 7) e sua correspondente curva de permanência. Para o ano de 2014 foi possível utilizar leituras horárias. Além disso, com a série histórica de N.A. de 1977 a 2013, destaca-se que a vazão máxima em Porto São José ocorreu em 1983 (N.A. $=8,74 \mathrm{~m})$ e a vazão mínima ocorreu em 2001 (N.A. = 1,12m). Entretanto, há registros de que em 1969 foi medida a menor vazão da série, $\operatorname{com} 2.800 \mathrm{~m}^{3} \cdot \mathrm{s}^{-1}$ (N.A. $\left.=0,42 \mathrm{~m}\right)$, período anterior a série de nível d'água disponível (a partir de 1977).

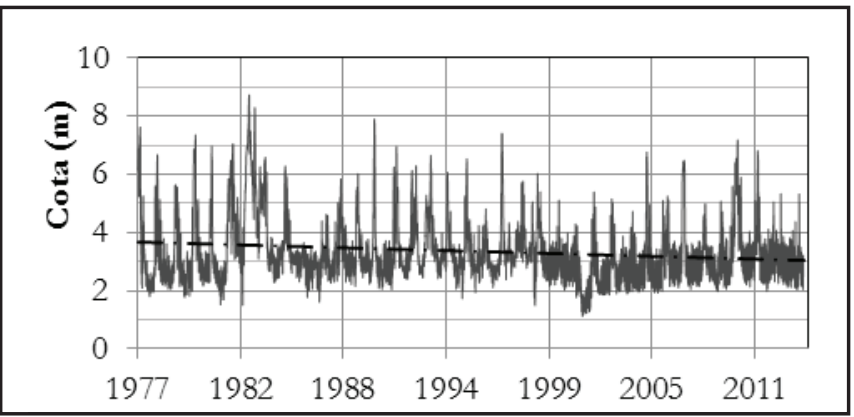

Figura 7 - Série histórica de nível d'água $(0<\mathrm{h}<9 \mathrm{~m})$ obtida através de três leituras diárias (N.A.) em Porto São José de 1977 a janeiro de 2014

A série histórica de nível d'água foi utilizada para identificar tendências ao longo do tempo e para determinar a curva de permanência, que é utilizada para determinar as frequências de ocorrência do N.A.

Tanto a série de N.A., quanto a curva de permanência 
são utilizadas como suporte para identificação da variação do N.A., em função das operações das UHEs.

\section{Batimetrias}

Os levantamentos batimétricos foram realizados na Estação de Porto São José, rio Paraná, de 1989 até 2014, sendo o ponto inicial (PI) na margem direita (Figura 8).

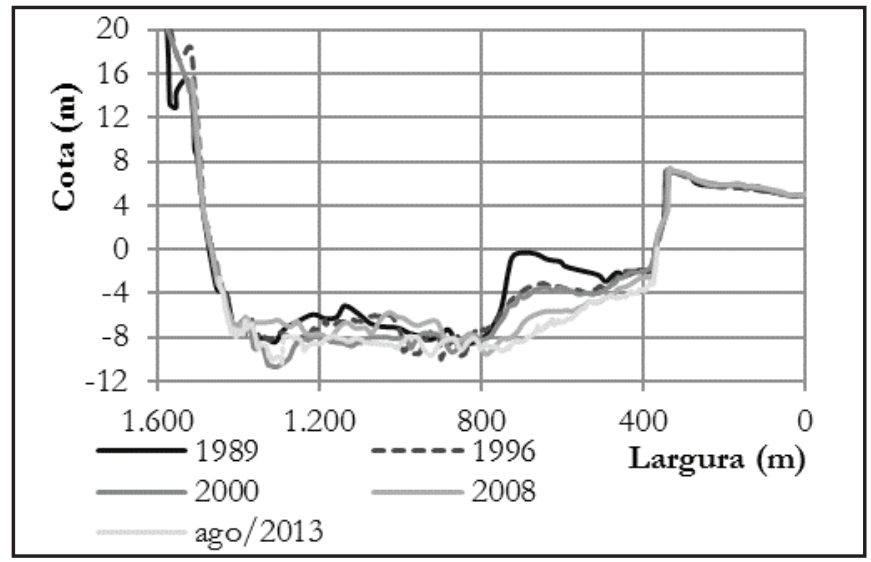

Figura 8 - Levantamentos Topo-Batimétricos realizados na Estação de Porto São José: 1989, 1996, 2000, 2008 e 2013

Em função da largura e profundidade da seção, os levantamentos batimétricos foram realizados por intermédio de teodolitos e ecobatímetros, e ultimamente com Sistemas de Posicionamento Global (GNSS).

Os levantamentos batimétricos foram utilizados para quantificar modificações do leito (e.g., assoreamento e/ou erosões) e determinar relações "cota x área" correspondente a cada período de tempo. O raio hidráulico, área e perímetro molhado, para cada cota,foram determinados em função do levantamento batimétrico de 2013.

\section{Curva-chave}

\section{A. Escoamento Permanente}

As curvas-chave correspondentes para cada período foram determinadas admitindo que a equação seja do tipo potencial (Equação 1) e que os coeficientes da equação sejam determinados pelo método dos mínimos quadrados, a partir das medições de vazão realizadas no respectivo período. Para isso, deve-se verificar se há linearidade da curva-chave quando plotada em um gráfico com escalas logarítmicas (HERSHY, 1978).

$\mathrm{Q}=\mathrm{c} \cdot(\mathrm{h}-\mathrm{a})^{\mathrm{n}}$

(Equação 1)

sendo “ $Q$ ” a vazão $\left(\mathrm{m}^{3} \cdot \mathrm{s}^{-1}\right)$, “h” o nível d'água $(\mathrm{m})$, “ $a$ ” nível d'água correspondente a vazão nula e " $c$ " e " $n$ " coeficientes.

Como não há medições de vazão para cotas superiores a $7 \mathrm{~m}$ (situação de extravasamento na margem direita para a planície de inundação), foi considerada a tabela de calibragem para o trecho superior da curva. A ausência de dados topográficos e de vazões medidas tornam os métodos de extrapolação inválidos e não aplicáveis. Em função da diferente rugosidade da calha extravasora comparada ao canal principal, métodos simples de velocidades tornam-se complexos (KHATUA; PATRA; MOHANTY, 2012). Com o desconhecimento deste tramo, a curva-chave pode resultar em vazões inferiores ao real, uma vez que a variação da vazão, em função da variação do nível d'água, tende a ser maior no tramo de extravasamento. Entretanto, esta hipótese fundamenta-se no aumento da área molhada (trecho extravasado de até $40 \mathrm{~km}$ de extensão) e não pode ser comprovada, tornando assim uma hipótese com restrições para N.A. maior que $7 \mathrm{~m}$.

\section{B. Escoamento não permanente}

Para que uma curva-chave $(\mathrm{Q} \times \mathrm{H})$ seja válida, o escoamento deve ser permanente, assim, para cada vazão medida existe um único valor de nível d'água correspondente. Entretanto, quando não ocorre a condição de escoamento permanente, a curva não representa o fenômeno hidráulico. Nestes casos, podem-se utilizar as seguintes metodologias (RANTZ et al., 1982):

a) curva-chave $(\mathrm{Q} \times \mathrm{H})$ para condição de escoamento permanente com correções $(\mathrm{dH} / \mathrm{dT})$, em função das ondas positivas e negativas que geram laços na curva ou histerese. Neste caso, se não corrigida, a curva indica valores inferiores ao real quando há ascensão do N.A. e superiores ao real quando há descenso do N.A. (MALDONADO; GAMARO, 2013). Neste método é necessário medir vazões em 3 condições hidrológicas: nível crescente, constante e nível decrescente;

b) curva-chave ( $\mathrm{Q}$ x dF) com duas estações fluviométricas, com o método do desnível d'água $(\mathrm{dF})$;

c) método da velocidade indexada $\left(\mathrm{V}_{\text {média }} \times \mathrm{V}_{\text {medida }}\right)$, com a instalação de um medidor de velocidade, como os medidores estáticos Doppler (SL).

Para a utilização e aplicação dos métodos (b) e (c), é necessária a instalação de uma infraestrutura adicional ao existente, tanto para medição de nível quanto de velocidade. $\mathrm{O}$ método (a) apresenta maior facilidade para aplicação prática, pois utiliza apenas uma estação fluviométrica. Entretanto, são necessárias constantes medições de vazão para verificação da validade do método.

Assim, foi aplicado o método (a), também chamado de Método de Wiggins, na Estação de Porto São José, para corrigir a curva-chave.

O método consiste na aplicação do acréscimo da linha de energia em função do acréscimo da velocidade (energia cinética), explicitada na Equação 2:

$$
\frac{Q_{c}}{Q_{m}}=\sqrt{1-\frac{1}{U \cdot S_{\varepsilon}} \cdot \frac{d H}{d T}}
$$

(Equação 2)

sendo, $Q_{c}$ a vazão corrigida $\left(\mathrm{m}^{3} \cdot \mathrm{s}^{-1}\right)$ em função do escoamento não ser permanente, $Q_{m}$ a vazão da curva-chave $\left(\mathrm{m}^{3} \cdot \mathrm{s}^{-1}\right)$ para condição de escoamento permanente, " $U$ " a velocidade de pro- 
pagação da onda $\left(\mathrm{m}_{\mathrm{s}} \mathrm{s}^{-1}\right), \mathrm{S}_{\mathrm{e}}$ a linha de energia para condição de escoamento permanente, $\mathrm{dH}$ a diferença de nível d'água (m) e dT a diferença de tempo entre as leituras de nível d'água (segundos).

A velocidade de propagação da onda (U), também chamada de celeridade da onda de cheia, é estimada como sendo de 1,3 a 1,7 vezes maior que a velocidade média $\left(\mathrm{V}_{\mathrm{m}}\right)$ da seção. Segundo Corbett (1945) o valor usual é de $1,3 . \mathrm{V}_{\mathrm{m}}$ e segundo Collischonn e Dornelles (2013), o valor da celeridade aproximase de $5 / 3 . V_{m}$. O coeficiente multiplicador da velocidade média $\left(\mathrm{V}_{\mathrm{m}}\right)$ adotado foi de 1,3, conforme recomendado por Rantz et al. (1982).

A linha de energia $\left(\mathrm{S}_{\mathrm{e}}\right)$ é estimada a partir da Equação de Manning (Equações 3 e 4):

$$
\begin{aligned}
& \frac{n \cdot Q}{\sqrt{S_{e}}}=A \cdot R_{h}^{2 / 3} \frac{n \cdot Q}{\sqrt{S_{e}}}=A \cdot R_{h}^{2 / 3} \\
& S_{\theta}=\frac{\left(n \cdot V_{m}\right)^{2}}{R_{h}^{4 / s}} S_{\theta}=\frac{\left(n \cdot V_{m}\right)^{2}}{R_{h}^{4 / s}}
\end{aligned}
$$

sendo, $\mathrm{V}_{\mathrm{m}}$ a velocidade média do escoamento e $\mathrm{R}_{\mathrm{h}} \mathrm{O}$ raio hidráulico da seção e " $n$ " o coeficiente de Manning.

Segundo Porto (2006), o coeficiente de Manning para arroios e rios varia de 0,025 a 0,150 , em função da rugosidade do canal.

Para se determinar o número de Manning correspondente à Estação de Porto São José foram comparadas as vazões medidas em campo e as vazões estimadas corrigidas $\left(\mathrm{Q}_{\mathrm{c}}\right)$ aplicando a equação 2, de modo iterativo.

Assim, foram comparadas as vazões mensais e diárias obtidas pela tabela de calibragem, nova curva-chave e curva-chave com correção (em função do escoamento não permanente), tendo como referência o somatório das defluências das UHEs. Deste modo, é possível identificar desvios de vazão para cada método e quanto as operações das UHEs influenciam na identificação da real vazão na Estação.

\section{RESULTADOS}

\section{Curva de Permanência}

Conforme a série histórica de nível d'água (Figura 7), nota-se que há uma tendência de diminuição do NA médio ao longo do tempo (1977 a 2014), fato parcialmente explicado com a entrada da operação das Usinas Hidrelétricas de Porto Primavera (rio Paraná) em 1999 e UHE Rosana (rio Paranapanema) em 1987. Em geral, as operações de Usinas tendem a diminuir a vazão máxima e aumentar a vazão mínima.

Segundo Rocha e Comunello (2002), quando o N.A. da Estação de Porto São José é maior que 4,60m ocorre o estágio de margens plenas, a partir do qual pode se iniciar a entrada das águas do rio Paraná pelos canais de ligação e lagoas, iniciando a inundação da parte mais baixa da Planície Fluvial.

A cota de 4,60m (início do processo de inundação da Planície Fluvial) ocorre com uma frequência de 10,6\% (Figura

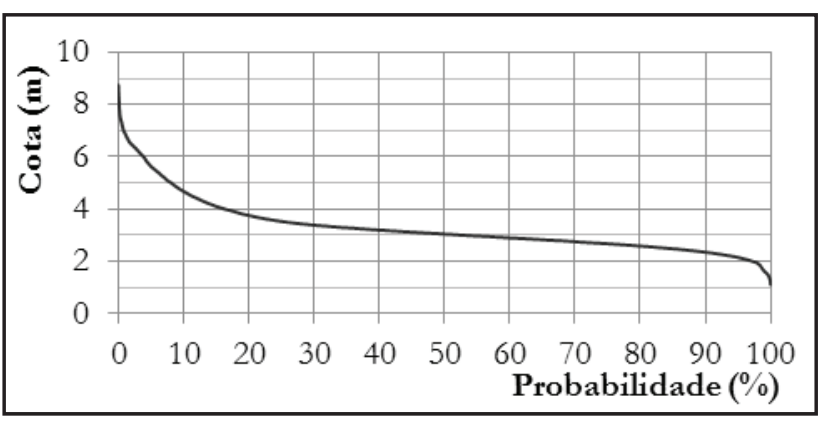

Figura 9-Curva de Permanência do N.A. para o período de 1977 a 2014 (0 a 100\%)

9) e em $80 \%$ do tempo o nível d'água está entre as cotas de $2 \mathrm{~m}$ e $4 \mathrm{~m}$.

\section{Dados geométricos da seção}

A partir dos levantamentos topo-batimétricos (Figura 8), nota-se que há um processo de erosão da margem direita da calha do rio ao longo do tempo, entre as distâncias de 500 a 800 metros, a partir do PI. Esta condição de erosão poderia ser parcialmente explicada pelo início da operação da UHE Porto Primavera em 1999 e UHE Rosana em 1987, considerando que as UHEs são estruturas hidráulicas que modificam as condições hidráulicas das seções à jusante, como a seção de Porto São José. Esta erosão indica uma dinâmica das condições morfológicas e hidráulicas e que o processo continuará evoluindo ao longo do tempo até haver um equilíbrio.

Além da erosão na margem direita (Figura 8), ocorre também uma variação sistemática do leito ao longo do tempo, identificada em outros trabalhos como deslocamento de fundo em formato de dunas (MARTINS, 2004) e (GAMARO; MALDONADO; BASTOLLA, 2014).

Considerando os levantamentos topo-batimétricos transversais, as relações "cota x área" são determinadas para auxiliar na construção da curva-chave. Assim, as relações "cota x área”, considerando as batimetrias de 1989 (Equação 5), 2000 (Equação 6) e 2013 (Equação 7), são:

$$
\begin{aligned}
& A=2,2492 \cdot H^{2}+1121,3 \cdot H+5502,2 \quad \text { (Equação 5) } \\
& A=3,4601 \cdot H^{2}+1114,4 \cdot H+7120,6 \quad \text { (Equação 6) } \\
& A=1,4234 \cdot H^{3}+7,7339 \cdot H^{2}+1076,5 \cdot H+7994,2
\end{aligned}
$$$$
\text { (Equação 7) }
$$

Como no levantamento de 2013 foram coletadas profundidades apenas na parte molhada da seção, anexou-se também a topografia do levantamento de 2008 (Equação7).

Comparando as áreas medidas, por intermédio das 147 medições de vazão realizadas pela Itaipu (1989 a 2014), com as áreas das relações "cotas x áreas", conclui-se que a área molhada da seção está aumentando ao longo do tempo (conforme verificado na Figura 8) e que para cada intervalo de tempo, deve-se utilizar a relação "cota x área" correspondente (Figura 10(a)). As outras características geométricas estão representadas na Figura10(b). 
Maldonado et al. Avaliação das modificações hidrológicas ocorridas na Estação de Porto São José, situada em um trecho do rio Paraná regulado por Usinas Hidrelétricas

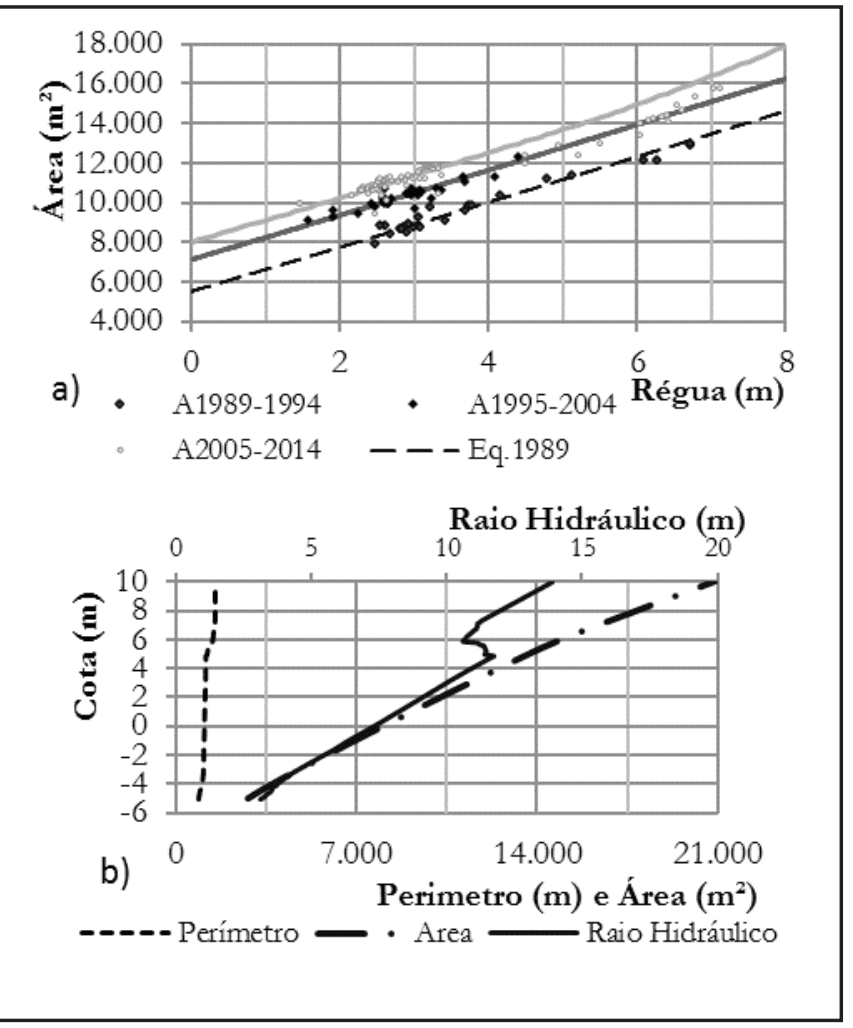

Figura 10 - (a) “Cota x área” (1989, 2000 e 2013) e áreas medidas de 1989 a 2014; (b) Características geométricas referentes à batimetria de 2013

Considerando o nível médio de 3,05m (50\% na curva de permanência de todo o período), a área correspondente para os perfis batimétricos para os anos de 1989, 2000 e 2013 é de $8.936 \mathrm{~m}^{2}, 10.549 \mathrm{~m}^{2}$ (aumento de 18\% comparado com 1989) e $11.435 \mathrm{~m}^{2}$ (aumento de $8,4 \%$ com 2000 e aumento de $28 \%$ com 1989), respectivamente.

\section{Velocidade média medida}

Considerando as 147 medições de vazão de 1989 a 2014, nota-se que a velocidade média da água está diminuindo ao longo do tempo (Figura 11). Para a cota média de 3,05m, a velocidade modificou-se de $0,94 \mathrm{~m} \cdot \mathrm{s}^{-1}$ para $0,75 \mathrm{~m} \cdot \mathrm{s}^{-1}$ (redução de $20 \%$ de 1991 a 2014).

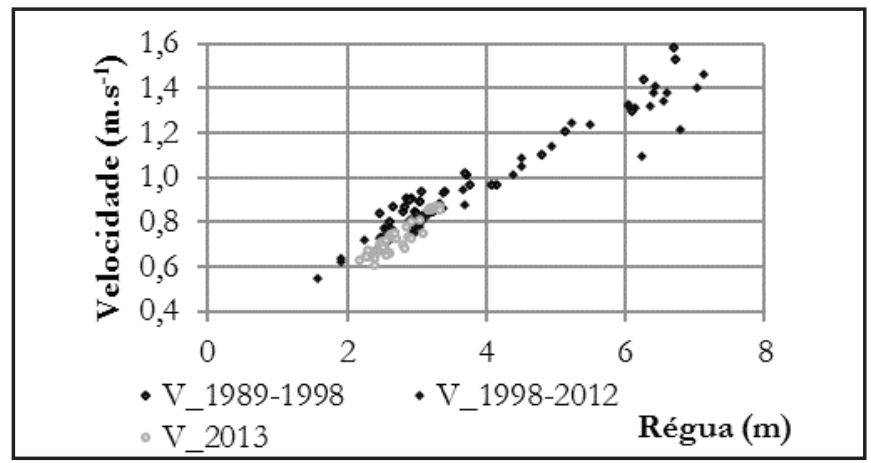

Figura 11 - Velocidades médias medidas de 1989 a 2014
A relação "nível x velocidade média" (Equação 8) de 2004 a 2014, é de:

$$
\mathrm{V}_{\mathrm{m}}=0,3282 \cdot \mathrm{H}^{0,8084}
$$

sendo $\mathrm{V}_{\mathrm{m}}$ a velocidade média $\left(\mathrm{m} \cdot \mathrm{s}^{-1}\right)$ e $\mathrm{H}$ o nível d'água (m).

\section{Vazões dedefluência, medida e estimada pela Tabela de Calibragem.}

A partir de 1994 as vazões estimadas pela tabela de calibragem resultam em valores inferiores às vazões medidas, com valor máximo de $-15 \%$ ou $1.350 \mathrm{~m}^{3} \cdot \mathrm{s}^{-1}$ (Figura 12(a)). A tendência negativa de desvios de vazão é um indicativo de que é necessária uma mudança da curva-chave na Estação de Porto São José.

Considerando os desvios de vazão, na ordem crescente de nível d'água (Figura 12(b)), nota-se que a tabela de calibragem resulta em valores inferiores às vazões medidas até a cota de $4 \mathrm{~m}$, havendo uma inversão de resultados para cotas superiores a $4 \mathrm{~m}$.

O método acústico de vazão começou a ser aplicado na Estação em 2005 e não foram identificadas diferenças significativasnos resultados entre os métodos. Segundo Gamaro (2012), os ADCPs de diferentes fabricantes estão aptos a medir as mais diversas características de rios e canais nacionais. Entretanto, a precisão de uma medição de vazão é extremamente dependente da escolha da frequência, modo de operação e tipo de processamento acústico.

A mudança dos desvios de vazão para cota superior a 4 m é um indício que há uma mudança hidráulica na seção e

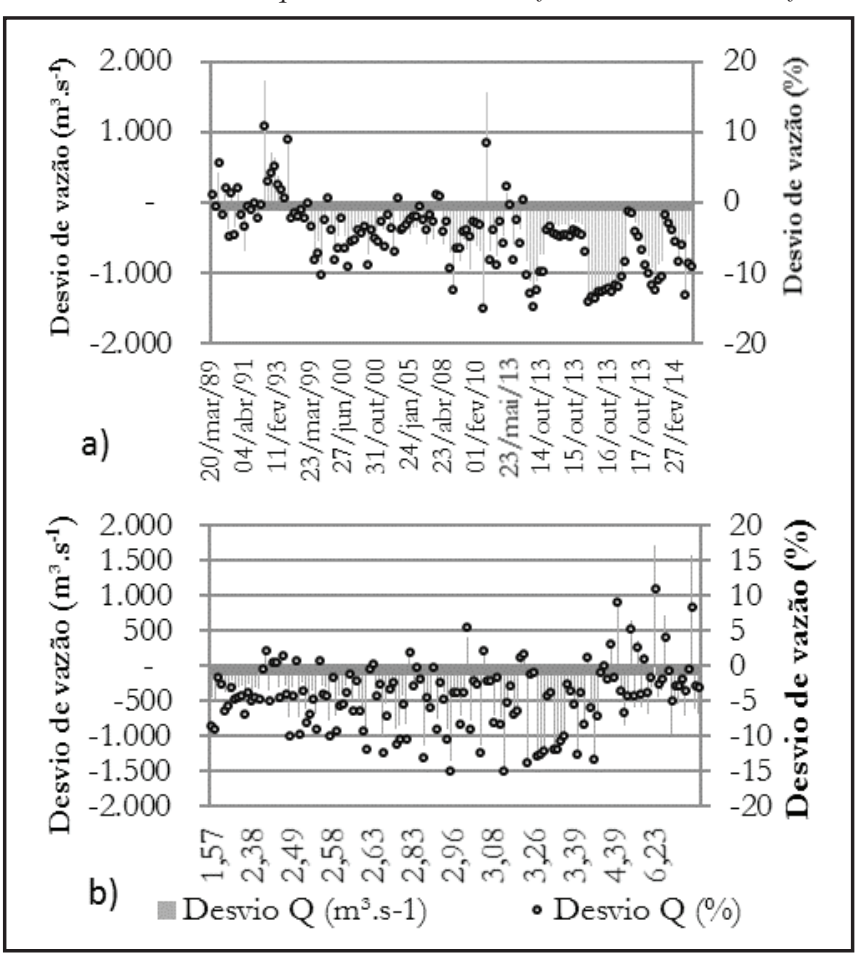

Figura 12 - Desvios de vazão entre a tabela de calibragem de 1983 e as medições realizadas entre 1989 e 2014. (a) ordem cronológica; (b) ordem crescente de nível d’água 
que pode estar havendo possíveis extravasamentos da água para a planície de inundação, situada na margem direita (MD).

Além disso, comparando as vazões de defluência diárias das UHE Porto Primavera e Rosana com as vazões médias diária em Porto São José, obtida pela Tabela de Calibragem, nota-se que há um desvio médio de $500 \mathrm{~m}^{3} \cdot \mathrm{s}^{-1}$ (Figura 13).

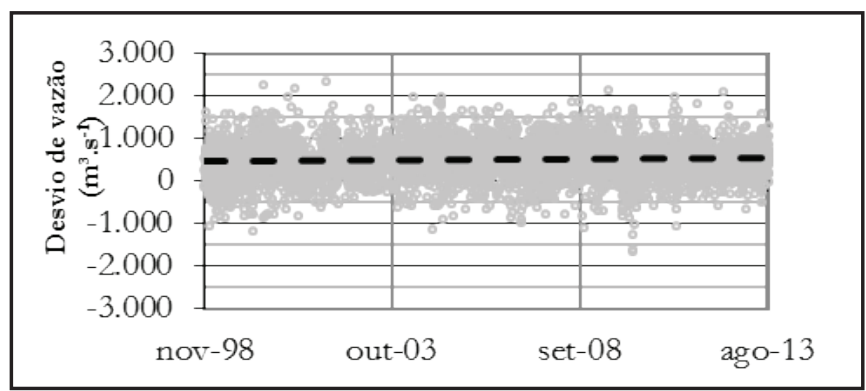

Figura 13 - Desvios de vazão entre o somatório das UHE Porto Primavera e a tabela de calibragem de Porto São José

\section{Nova curva-chave para a Estação de P. S. José}

Considerando as alterações do leito do rio Paraná, conforme resultado dos levantamentos batimétricos de 1989 a 2013 (Figura 8), nota-se que é preciso determinar uma curva-chave para cada período correspondente. Assim, aplicou-se a Equação 1 e foram determinadas as curvas-chave para os períodos de 1995 a 2004 (Equações 9 e 10) e de 2005 a 2014 (Equações 11 e 12):

Período de 1995 a 2004:

$$
\begin{aligned}
& 0,10<\mathrm{H}<7,01 \mathrm{~m} \\
& \mathrm{Q}=334,31 .(\mathrm{h}+3)^{1,79406}
\end{aligned}
$$

(Equação 9)

Desvios médios de vazão entre: -2,5 e 2,5\%;

$$
\begin{aligned}
& 7,01 \mathrm{~m}<\mathrm{H}<9,50 \mathrm{~m} \\
& \mathrm{Q}=298,48 .(\mathrm{h})^{2,1804}
\end{aligned}
$$

Período de 2005 a 2014:

$$
\begin{aligned}
& 0,10<\mathrm{H}<7,32 \mathrm{~m} \\
& \mathrm{Q}=159,59 .(\mathrm{h}+4)^{2,0469}
\end{aligned}
$$

Desvios médios de vazão entre: -4,1 e 3,6\%;

$$
\begin{aligned}
& 7,32 \mathrm{~m}<\mathrm{H}<9,50 \mathrm{~m} \\
& \mathrm{Q}=298,48 .(\mathrm{h})^{2,1804}
\end{aligned}
$$

Para as cotas superiores a borda plena (acima de 7,0m na $\mathrm{MD}$ ), deve-se utilizar a curva-chave com ressalvas, pois quase não há medições de vazão nestas condições. Assim, devem-se realizar novas medições de vazão quando ocorrer uma condição de cheia e verificar, assim, a validade do tramo superior da curva-chave proposta.
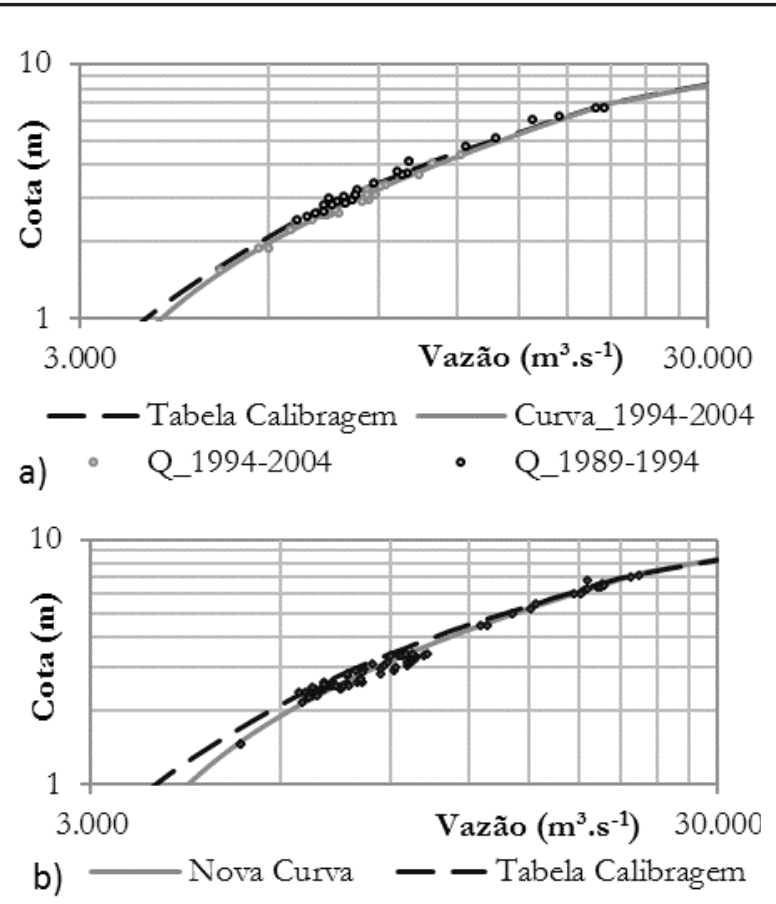

Figura 14 - Medições de vazão e a curvas-chave para os períodos: (a) de 1994 a 2004; (b) 2005 a 2014

\section{Escoamento não permanente}

Para determinar o número de Manning, correspondente à Estação de Porto São José, foram comparadas as vazões medidas em campo com as vazões estimadas corrigidas $\left(Q_{c}\right)$ aplicando as equações 2, 4 e 11, de modo iterativo (Figura 15).

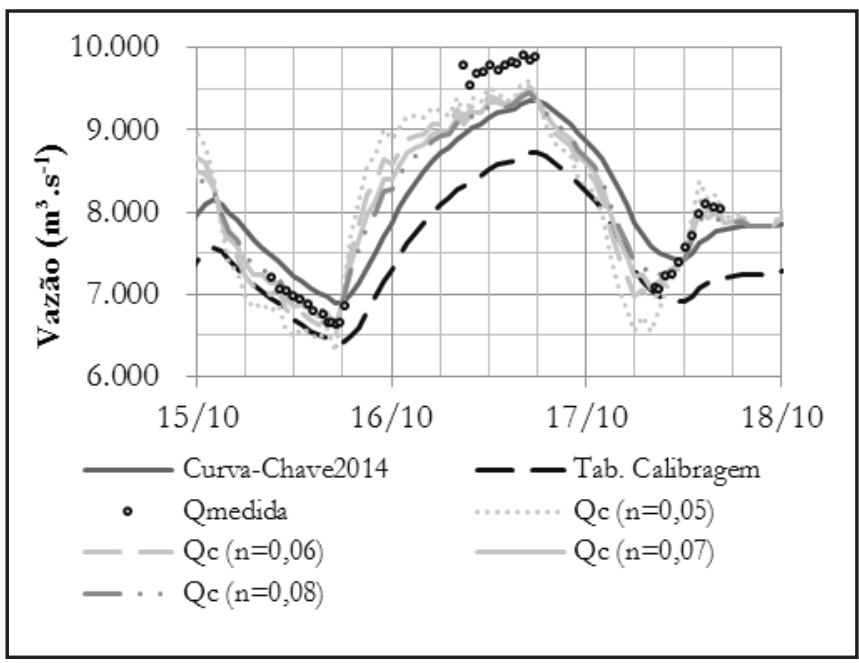

Figura 15 - Vazões obtidas pela curva-chave de 2014 (Equação 11), pela correção da histerese (Equação 2, considerando os coeficientes de Manning de 0,05 a 0,08) e por medições em campo

Assim, considerando as vazões medidas de 2013 e 2014, o coeficiente de Manning que melhor se adequa é o valor de 0,065 (Figura 15). 
A Equação 2 pode ser simplificada inserindo a equação $8\left(\mathrm{~V}_{\mathrm{m}}\right)$ e equação $4\left(\mathrm{~S}_{\mathrm{e}}\right)$, os coeficientes da celeridade de 1,3 e de Manning de 0,065, para um intervalo de tempo de uma hora, obtendo a Equação 13:

$$
Q_{c}=Q_{m} \cdot \sqrt{1-\frac{d H \cdot R_{h}^{4 / 3}}{0,699 \cdot H^{2,4252}}}
$$

sendo $Q_{m}$ a vazão da curva-chave (Equações 11 e 12), H o nível d'água $(\mathrm{m}), \mathrm{dH}$ a variação de nível d'água $(\mathrm{m})$ para um intervalo de uma hora $\left(\mathrm{dH}=\mathrm{H}_{0}-\mathrm{H}_{1}\right.$, sendo $\mathrm{H}_{1} \mathrm{o}$ nível d'água atual e $\mathrm{H}_{0}$ o nível d'água de uma hora antes) e $\mathrm{R}_{\mathrm{h}} \mathrm{O}$ raio hidráulico (Figura 10(b)).

Assim, foram comparadas as vazões para o ano de 2014, considerando a Equação 13 (escoamento não permanente), Equações 11 e 12 (curva-chave para escoamento permanente), tabela de calibragem e as vazões de defluência das Usinas de Porto Primavera e Rosana (Figura 16).

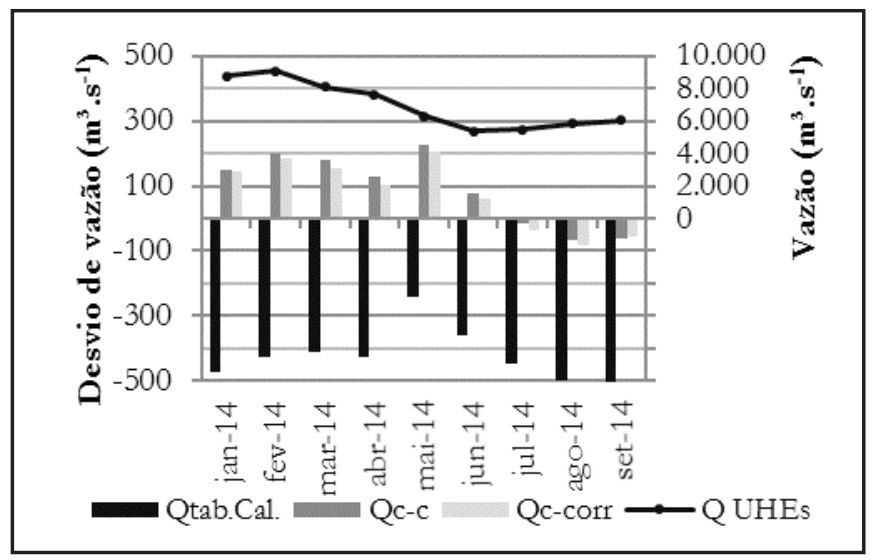

Figura 16 - Desvios de vazão mensal, considerando como referência o somatório das defluências das UHEs

Considerando os desvios mensais de vazão (Figura 16), nota-se que a tabela de calibragem indica desvios inferiores (420 $\mathrm{m}^{3} \cdot \mathrm{s}^{-1}$ ) com o somatório das UHEs (conforme verificado na Figura 13). Os desvios de vazão para a nova curva-chave, para condição de escoamento permanente (Equações 11 e 12) e para escoamento não permanente (Equação 13) apresentaram desvios médios mensal de 90 e $75 \mathrm{~m}^{3} \cdot \mathrm{s}^{-1}$, respectivamente, comparados ao somatório das defluências das UHEs.

Para os desvios de vazão diários, enquanto a tabela de calibragem indica desvios de $430 \mathrm{~m}^{3} \cdot \mathrm{s}^{-1}$, a curva-chave para escoamento permanente (Equações 11 e 12) resulta em um desvio médio diário de $85 \mathrm{~m}^{3} \cdot \mathrm{s}^{-1}$ e para escoamento não permanente (Equação 13) resulta em desvio médio diário de $70 \mathrm{~m}^{3} \cdot \mathrm{s}^{-1}$, comparados ao somatório das defluências das UHEs.

Assim, a nova curva-chave com escoamento não permanente (Equação 13) foi o método que melhor representou as vazões na Estação de Porto São José nas comparações com as defluências das UHEs.

De modo a quantificar o erro horário da aplicação da tabela de calibragem e da curva-chave para escoamento permanente (Equações 11 e 12), foram comparadas as vazões na Estação de Porto São José entre os métodos (Figura 17).

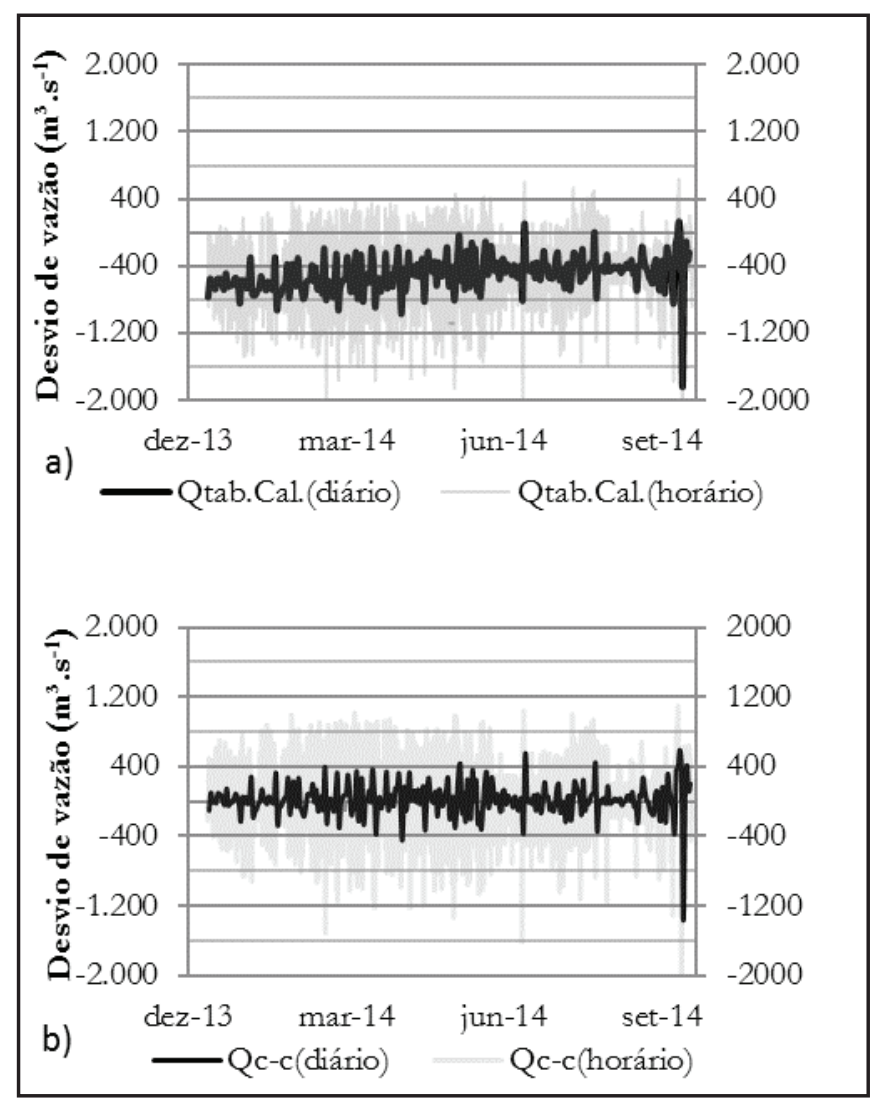

Figura 17 - Desvios de vazão diários e horários, considerando como referência a vazão obtida pela curva-chave de 2014 para condição de escoamento não permanente: (a) tabela de calibragem (Qtab. Cal.); (b) curva-chave (Equações 11 e 12) (Qc-c)

Conforme figura 17 , considerando a vazão obtida pela Equação 13 como a referência, nota-se que a Tabela de Calibragem resulta em desvios de vazão horários na faixa de $+130 \mathrm{~m}^{3} \cdot \mathrm{s}^{-1} \mathrm{a}-1.150 \mathrm{~m}^{3} \cdot \mathrm{s}^{-1}$ e média de $-500 \mathrm{~m}^{3} \cdot \mathrm{s}^{-1}$. Os desvios diários resultaram na faixa de $+180 \mathrm{~m}^{3} \cdot \mathrm{s}^{-1} \mathrm{a}-790 \mathrm{~m}^{3} \cdot \mathrm{s}^{-1}$. Os limites indicados na faixa de desvios de vazão foram obtidos por intermédio da ocorrência de $95 \%$ e $5 \%$ dos respectivos desvios de vazão.

Com a aplicação da curva-chave obtida pelas equações 11 e 12, os desvios de vazão horários resultaram na faixa de $+640 \mathrm{~m}^{3} \cdot \mathrm{s}^{-1} \mathrm{a}-610 \mathrm{~m}^{3} \cdot \mathrm{s}^{-1}$ (média de $17 \mathrm{~m}^{3} \cdot \mathrm{s}^{-1}$ ) e desvios diários na faixa de $+330 \mathrm{~m}^{3} \cdot \mathrm{s}^{-1}$ a $-250 \mathrm{~m}^{3} \cdot \mathrm{s}^{-1}$.

Apesar de haver um desvio médio horário e diário de vazão próximo de nulo $\left(17 \mathrm{~m}^{3} \cdot \mathrm{s}^{-1}\right)$, as operações das UHEs impactam diretamente nas vazões estimadas na Estação de Porto São José, pois as operações das UHEs ocasionam ondas positivas e/ou negativas no trecho, modificando o escoamento para não permanente. Quanto maior a variação horária das defluências, maiores são os desvios de vazão identificados na Estação de Porto São José (e.g., para o dia 29/09/2014, figura 17, o desvio horário de vazão foi de $1.950 \mathrm{~m}^{3} \cdot \mathrm{s}^{-1} \mathrm{e}$ diário de $1.360 \mathrm{~m}^{3} \cdot \mathrm{s}^{-1}$ ).

$\mathrm{Na}$ figura 18 seguem dois exemplos do comportamento 
de cada curva-chave na Estação de Porto São José e da soma das defluências das UHEs. Para o primeiro caso, nota-se que nos primeiros momentos do dia 21/07/2014 as curvas-chave de 2014 (tanto para escoamento permanente, quanto para não permanente) se comportam de modo similar às somas das defluências das UHEs e a tabela de Calibragem não condiz com a realidade. Entretanto, quando as defluências variaram de 5.100 $\mathrm{m}^{3} \cdot \mathrm{s}^{-1}$ para $6.500 \mathrm{~m}^{3} \cdot \mathrm{s}^{-1}$, somente a curva-chave representada pela Equação 13 se comportou de modo similar a soma das defluências das UHEs.

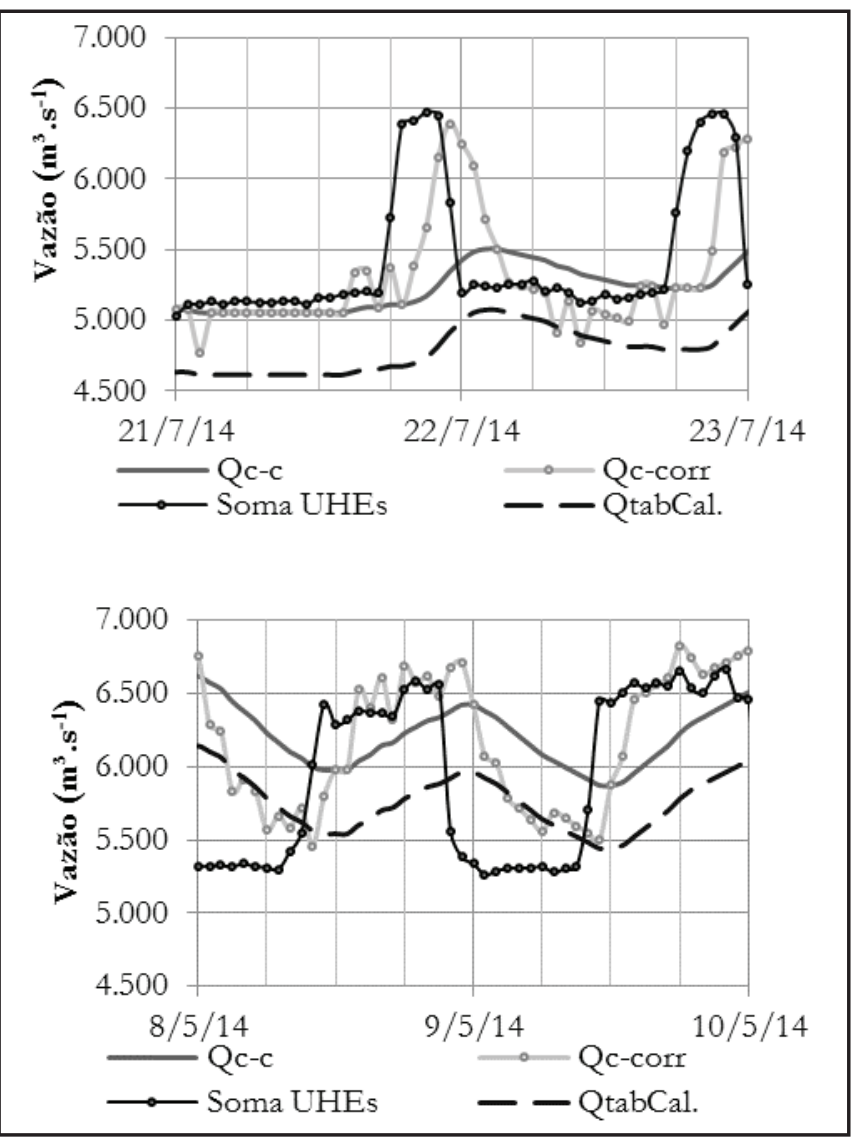

Figura 18 - Vazões horárias, considerando a curva-chave de 2014 (Qc-c), a curva-chave corrigida em função da histerese (Qc-corr), o somatório das vazões defluentes das UHEs (Soma UHEs) e tabela de calibragem (QtabCal.)

\section{CONCLUSÕES}

O conhecimento das variáveis hidrológicas e de suas dinâmicas ao longo do tempo é de suma importância para a gestão dos Recursos Hídricos. Alterações destas variáveis podem ser ocasionadas por ações antrópicas, como a regularização de vazões, devendo ser entendidas e corrigidas.

Para a Estação de Porto São José, situada à jusante de duas UHEs, por intermédio das medições de vazão e das batimetrias, foi possível identificar,de 1989 a 2013, que está ocorrendo um processo de erosão na seção na ordem de $28 \%$, redução da velocidade média de $20 \%$, para o nível médio de 3,05m, e redução do N.A. médio.
Considerando o somatório de defluência das UHEs, a tabela de calibragem apresentou desvios médios mensais de vazão de $500 \mathrm{~m}^{3}$. $\mathrm{s}^{-1}$.Como há o efeito de histerese, em função das variações das operações das UHEs, a tabela de calibragem indicou desvios de vazão horários de até $-1.950 \mathrm{~m}^{3} \cdot \mathrm{s}^{-1}$ e desvios diários de até $-1.360 \mathrm{~m}^{3} . \mathrm{s}^{-1}$.

Assim, a utilização da tabela de calibragem ocasionam grandes erros para a determinação da vazão em Porto São José e as operações das UHEs de Porto Primavera e Rosana modificam os escoamentos para não permanentes, aumentando o grau de complexidade para a determinação da real vazão.

De modo geral, somente com campanhas e coletas de campo, de modo contínuo, é possível identificar e quantificar alterações das condições hidrológicas e hidráulicas das estações fluviométricas. Hidrogramas mesmo considerados consistidos podem conter erros, como no caso da série de Porto São José.

Além da necessidade do continuo monitoramento da área molhada e da velocidade média da seção, é fundamental a aplicação da correção da curva-chave de PSJ (condição de escoamento não permanente), tanto para escala horária, quanto diária, para que se tenha o real hidrograma para a Estação.

\section{REFERÊNCIAS}

CAMPAGNOLI, F.; DINIZ, N. C. Gestão de reservatórios de bidrelétricas. São Paulo: Oficina de Texto, 2012.

\section{COLLISCHONN, W. E DORNELLES, F. Hidrologia para} engenharia e ciências ambientais. Porto Alegre: ABRH, 2013.

CORBETT, D. M. Stream-Gaging Procedure. A manual describing methods and practices of the Geological Survey. Washington: United States Government Printing, 1945. (Water-Supply paper 888).

GAMARO, P. E. M. Medidores Acústicos Doppler de Vazão. Foz do Iguaçu: [s.n.], 2012.

GAMARO, P. E. M.; MALDONADO, L. H.; BASTOLLA, V. Using dunes displacement method to estimate bed load in Paraná river. In: Int. Conf. Large Rivers, 2., 2014, Manaus. Proceedings... [S.l.: s.n.], 2014.

\section{GOOGLE Earth. 2014.}

HERSHY, R. W. Hydrometry. Principles and practices. 2nd ed. [S.1.]: Wiley, 1978.

ISO. ISO 24154: Hydrometry - Measuring river velocity and discharge with acoustic Doppler profilers. [S.1.]: ISO, 2005.

ITAIPU. Relatório referente à campanha de medição de vazão em Porto São José e a jusante das UHE Porto Primavera e Rosana. [S.1.]: Itaipu, 2013.

JACCON, G.; CUDO, K. J. Curva-Chave. Análise e Traçado. 
Brasília: DNAEE, 1989.

JALBERT, J.; MATHEVET, T.; FAVRE, A. C. Temporal uncertainty estimation of discharges from rating curves using a variographic analysis. J. Hydrology, v. 397, n. 1-2, p. 83-92, Jan. 2011.

KHATIBI, R.; SIVAKUMAR, B.; GHORBANI, M. A.; KISI, O.; KOÇAK, K.; ZADEH, D. F. Investigating chaos in river stage and discharge time series. J. Hydrol., v. 414-415, p. 108117, Jan. 2012.

KHATUA, K. K.; PATRA, K. C.; MOHANTY, P. K. StageDischarge Prediction for Straight and Smooth Compound Channels with Wide Floodplains. J. Hydraulic Eng., v. 138, n. 1, p. 93-99, Jan. 2012.

MALDONADO, L. H.; GAMARO, P. E. M. Métodos de correção de vazões em tramos superiores de curvas-chaves e para o caso de histerese. In: SIMPÓSIO BRASILEIRO DE RECURSOS HÍDRICOS, 20., Bento Gonçalves, RS, 2013. Anais... Porto Alegre: ABRH; 2013.

MANYARI, W. V. Impactos ambientais a jusante de hidrelétricas, o caso da usina Tucurui-PA. 2007. 222 f. Tese (Doutorado de Engenharia) - Universidade Federal do Rio de Janeiro, Rio de Janeiro, 2007.

MARTINS, D. P. Dinâmica das Formas de Leito e Transporte de Carga de Fundo no Alto rio Paraná. 2004. 66 f. Dissertação (Mestrado em Geografia) - Centro de Ciências Humanas, Letras e Artes, Universidade Estadual de Maringá, Maringá, 2004.

MÜLLER, A. C. Hidrelétricas, meio ambiente e desenvolvimento. São Paulo: Makron Books, 1995.

MUELLER, D. S.; WAGNER, C. R.; REHMEL, M. S.; OBERG, K. A.; RAINVILLE, F. Measuring discharge with acoustic Doppler current profilers from a moving boat. (ver. 2.0, December 2013). Washington: U.S. Geological Survey Techniques and Methods, 2013. Book 3, chap. A22.

PORTO, R. M. Hidráulica básica. São Carlos: EESC/USP, 2006.

RANTZ, S. E. et al. Measurement and computation of streamflow. Washington: USGS, 1982. v. 2. (Geological survey water-supply paper, 2175).

ROCHA, P. C.; COMUNELLO, E. Geomorfologia e áreas inundáveis na Planície Fluvial do Alto rio Paraná. 2002.

SIQUEIRA, A. G.; AZEVEDO, A. A.; SOUZA, L. A. P.; SILVA, M. Modificações fluviais à jusante de barragens. In: CONGRESSO BRASILEIRO DE GEOLOGIA DE ENGENHARIA E AMBIENTAL, 14., Rio de Janeiro, 2013. Anais... [S.l.: s.n.], 2013.

SOUSA, W. L. Impacto ambiental de hidrelétricas:uma análise comparativa de duas abordagens. 2000. 160 f. Dissertação (Mestrado de Engenharia) - Universidade Federal do Rio de Janeiro, Rio de Janeiro, 2000.

WMO - World Meteorological Organization. Manual on Stream Gauging. Geneva: Chairperson, 2010. V. 1. (WMO, nº 1044). 